\title{
Redução da expressão astrocitária de proteína glial fibrilar ácida em cães tratados com dexametasona
}

\author{
Decrease in the astrocytic expression of glial fibrillary acidic protein in dogs treated with \\ dexamethasone
}

\author{
Eduardo Fernandes Bondan ${ }^{\mathrm{I}, \mathrm{II}^{*}}$ Rogério Loesch Zacariotti ${ }^{\mathrm{II}}$ \\ Maria de Fátima Monteiro Martins, ${ }^{\mathrm{I}, \mathrm{II}}$ Flávio Cesar Viani ${ }^{\mathrm{II}}$
}

\section{- NOTA -}

\section{RESUMO}

A proteina glial fibrilar ácida (GFAP) constitui o principal marcador dos astrócitos, as células gliais mais numerosas do tecido nervoso e que exibem receptores a diversos hormônios esteroidais, os quais exercem aparente influência sobre a expressão gênica das mesmas. O objetivo do presente estudo foi o de avaliar se a administração de dexametasona (DX) em protocolos terapêuticos para cães seria capaz de afetar a expressão astrocitária dessa proteína. Para tal, amostras da ponte e da medula espinhal torácica de cães, tratados $(n=6)$ ou não (n=6) com DX, foram submetidas à marcação imunohistoquímica para a GFAP e a reatividade astrocitária foi determinada por colorimetria em um sistema computacional de análise de imagens. Diferença estatisticamente significativa foi constatada para as médias das áreas marcadas para GFAP na ponte de cães tratados e não-tratados com DX, assim como na medula espinhal torácica dos que haviam recebido previamente o corticoide ou não, com clara tendência, induzida pela droga, de redução da expressão astrocitária da proteína. Além disso, a expressão de GFAP na medula espinhal foi maior que na ponte, independentemente do emprego de DX ou não.

Palavras-chave: astrócitos, cães, corticoide, dexametasona, GFAP, imuno-histoquímica.

\section{ABSTRACT}

Glial fibrillary acidic protein (GFAP) is the most important marker of astrocytes, that are the major glial cells in the nervous tissue and exhibit receptors to several steroid hormones, which have an apparent influence in their genic expression. The aim of this study was to evaluate if dexamethasone (DX) administration in therapeutic protocols to dogs would be capable of affecting the astrocytic expression of the protein. Samples from the pons and the spinal cord of dogs, treated $(n=6)$ or not ( $n=6)$ with DX, were submitted to GFAP immunohistochemical staining and astrocytic reactivity was determined by colorimetry in a computer system for image analysis. Difference statistically significant was noted for the mean areas stained with GFAP in the pons of dogs treated and non-treated with DX, as well as in the spinal cord of dogs which previously received or not DX, with clear tendency of drug-induced reduction in the astrocyte expression of this protein. GFAP expression in the spinal cord was greater than in the pons, regardless the use of DX or not.

Key words: astrocytes, corticoid, dexamethasone, dogs, GFAP, immunohistochemistry.

Modificações na estrutura química do glicocorticoide cortisol acabaram por gerar corticosteroides sintéticos, tais como a dexametasona (DX), considerada 30 vezes mais potente que o cortisol quanto a sua potência anti-inflamatória, embora com diminuição de seus possíveis efeitos mineralocorticoides. As propriedades anti-inflamatórias e imunomoduladoras da DX são amplamente aproveitadas na clínica médica veterinária e o fármaco é empregado em uma grande variedade de condições patológicas (GUILPAIN \& LE JEUNNE, 2012).

Os glicocorticoides difundem-se em quase todas as células e ligam-se no citoplasma a proteínas receptoras para regular a expressão de genes responsivos a corticoides. Determinam modificação

'Programa de Pós-graduação em Patologia Ambiental e Experimental, Universidade Paulista (UNIP), São Paulo, SP, Brasil.

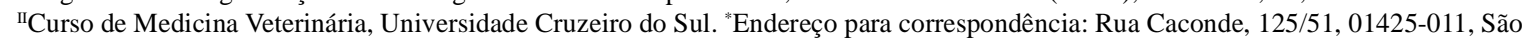

Paulo, SP, Brasil. E-mail: bondan@uol.com.br. 
conformacional nos receptores e sua translocação ao núcleo, onde ativam a transcrição gênica. $\mathrm{O}$ mRNA resultante, então, ativa no citoplasma a síntese de proteínas específicas e peptídeos reguladores que controlam a função celular. Embora geralmente haja aumento na expressão de genes-alvo, os corticoides podem diminuir a transcrição desses genes, como ocorre com algumas citocinas, cuja regulação inibitória tem importante papel nas ações antiinflamatórias e imunossupressoras dos corticoides (GUILPAIN \& LE JEUNNE, 2012).

Os hormônios esteroides são capazes de afetar um amplo espectro de funções neurais, já que facilmente atravessam a barreira hematoencefálica e transmitem informação a neurônios e células gliais no sistema nervoso central (SNC). Tem sido demonstrado que astrócitos e oligodendrócitos possuem receptores intracelulares clássicos para muitas famílias de hormônios esteroidais, tais como glicocorticoides, mineralocorticoides, andrógenos, estrógenos e progesterona (MELCANGI et al., 2001).

A proteína glial fibrilar ácida (GFAP) constitui o principal componente estrutural dos astrócitos de indivíduos adultos (MONTGOMERY, 1994; SOFRONIEW \& VINTERS, 2010), sendo a imuno-histoquímica o principal método utilizado na identificação da expressão dessa proteína, que é relativamente específica para a população astrocitária.

Uma vez que os corticosteroides são capazes de modificar a expressão gênica de várias proteínas gliais in vitro e in vivo em roedores sob condições experimentais, este estudo tem por objetivo identificar se a administração terapêutica de antiinflamatórios esteroidais em cães é também capaz de promover modificações detectáveis na expressão astrocitária da proteína GFAP.

Foram utilizadas amostras de tecido nervoso, obtidas da ponte e do $1^{\mathrm{o}}$ segmento da medula espinhal torácica (T1), de 12 cães que vieram a óbito por diferentes causas, pertencentes a distintas raças, idades e sexos e que se adequavam a critérios de preservação tecidual previamente determinados. Destes, seis haviam sido tratados com DX nos últimos 15 dias (com doses variáveis de $1 \mathrm{a} 3 \mathrm{mg} \mathrm{kg}^{-1}$, por via intramuscular a intervalos regulares de 4-6 horas, por um período máximo de sete dias) e seis eram cães clinicamente sadios, sem lesões observáveis no $\mathrm{SNC}$ e sem qualquer administração de fármacos nos últimos 15 dias.

Após prévia fixação em formol tamponadoa $10 \%$ por período sempreinferior a sete dias, as amostras colhidas foram incluídas em parafina e submetidas à marcação imuno-histoquímica da GFAP pelo método indireto do complexo avidina-biotina-peroxidase (ABC). Cortes histológicos de $5 \mu \mathrm{m}$ de espessura foram inicialmente corados com hematoxilina-eosina (HE) para avaliação da integridade do tecido nervoso na amostra. Descartada a presença de qualquer possível alteração histopatológica, cortes histológicos foram feitos em lâminas silanizadas. A marcação da proteína glial seguiu o método utilizado por ORSINI et al. (2007) em seu estudo com cães. Os cortes colhidos em lâminas silanizadas foram desparafinizados em xilol e hidratados em uma sequência decrescente de etanóis. Foram, então, incubados durante 24 horas, a $4^{\circ} \mathrm{C}$, com anticorpo primário policlonal anti-GFAP (rabbit anticow GFAP, ZO334, Dako), padronizado na diluição 1:1000. Posteriormente, foram incubados por uma hora com o anticorpo secundário biotinilado antiimunoglobulinas de camundongo (Novostain Super ABC Kit, Novocastra), na diluição 1:100, e, após, com o conjugado estreptavidina-biotina-peroxidase (Novostain Super ABC Kit, Novocastra) por mais uma hora. A imunorreatividade foi visualizada pela aplicação sobre os cortes de diaminobenzidina (DAB, Sigma) a $0,1 \%$ como cromógeno e peróxido de hidrogênio a $0,5 \%$. Os cortes foram contracorados com hematoxilina, desidratados, diafanizados e montados com resina sintética sob lamínula. Todas as reações foram acompanhadas por lâminas de controle negativo, submetidas a todas as etapas do procedimento, exceto à aplicação do anticorpo primário.

Áreas de $302.952,5 \mu \mathrm{m}^{2}$ dos cortes submetidos à prova imuno-histoquímica foram analisadas em microscópio de luz (com objetiva de 10x), para avaliação da imunorreatividade das células marcadas para GFAP. A reatividade astrocitária foi determinada por colorimetria em um sistema computacional de análise de imagens, o Image Pro-Plus 4.5 (Media Cybernetics, Silver Spring, EUA), quantificando, em $\mu \mathrm{m}^{2}$, a área marcada em castanho contida na área total de $302.952,5 \mu \mathrm{m}^{2}$. Os resultados numéricos foram submetidos à análise estatística, utilizando-se os testes de Wilcoxon e de Mann-Whitney, respectivamente, para as amostras pareadas e não-pareadas e adotando-se um nível de significância de 5\%.

Diferença estatisticamente significativa foi constatada para as médias das áreas marcadas para GFAP (Tabela 1) na ponte de cães tratados $(6219,21 \pm 1084,56)$ e não-tratados com DX $(8682,73 \pm 527,73)(\mathrm{P} \leq 0,05)$, assim como na medula espinhal torácica dos que haviam recebido previamente o corticoide $(7674,91 \pm 1028,09)$ ou não $(11620,85 \pm 1544,25)$ $(\mathrm{P} \leq 0,05)$, com clara tendência, induzida pela droga, de redução da expressão astrocitária da proteína. Foi 
Tabela 1- Áreas em $\mu \mathrm{m}^{2}$ com marcação para GFAP de uma área total de $302952,5 \mu \mathrm{m}^{2}$ para os animais que receberam ou não tratamento com dexametasona (DX).

\begin{tabular}{|c|c|c|c|c|}
\hline & Ponte $\left(\mu \mathrm{m}^{2}\right)$ & $\mathrm{T} 1\left(\mu \mathrm{m}^{2}\right)$ & Ponte $\left(\mu \mathrm{m}^{2}\right)$ & $\mathrm{T} 1\left(\mu \mathrm{m}^{2}\right)$ \\
\hline Cão 1 & 7906,71 & 8126,32 & 9352,74 & 14123,24 \\
\hline Cão 2 & 5124,36 & 8833,48 & 8214,69 & 12413,72 \\
\hline Cão 3 & 5017,26 & 6118,34 & 8326,70 & 10841,23 \\
\hline Cão 4 & 6841,15 & 7875,86 & 9116,24 & 9760,43 \\
\hline Cão 5 & 6254,31 & 8336,12 & 8112,43 & 10681,12 \\
\hline Cão 6 & 6171,49 & 6759,35 & 8973,57 & 11905,37 \\
\hline Média & $6219,21^{\mathrm{a}}$ & $7674,91^{\mathrm{c}}$ & $8682,73^{b}$ & $11620,85^{\mathrm{d}}$ \\
\hline Desvio-padrão & $\pm 1084,56$ & $+1028,09$ & $+527,73$ & $+1544,25$ \\
\hline
\end{tabular}

T1- primeiro segmento da medula espinhal torácica

Letras distintas indicam diferença estatisticamente significativa $(P \leq 0,05)$

também observada diferença significativa $(\mathrm{P} \leq 0,05)$ na expressão de GFAP entre as duas regiões analisadas (ponte $\mathrm{x}$ medula espinhal), sendo maior na medula espinhal do que na ponte, tanto no grupo tratado com DX quanto no não-tratado.

Os resultados correlacionando o uso de corticoides e a resposta astrocitária são controversos. Os glicocorticoides são conhecidos por modularem a expressão de uma variedade de proteínas gliais, incluindo GFAP, glutamina sintetase, proteína básica da mielina (MBP) e glicerol-fosfato desidrogenase (JUNGTESTAS et al., 1994; CHENG \& de VELLIS, 2000).

De forma semelhante à encontrada em nosso estudo, tratamentos in vivo com corticosterona e outros corticoides, como DX, revelaram inibir a expressão de GFAP no encéfalo de ratos neonatos e adultos. Já a adrenalectomia mostrou aumentar os níveis de mRNA e da proteína GFAP, o que foi posteriormente revertido com a administração de corticosterona (O'CALLAGHAN et al., 1991; MELCANGI et al., 2001).

No entanto, um padrão distinto de atividade foi encontrado com a corticosterona in vitro, já que a exposição de astrócitos em cultivo a este esteroide foi capaz de induzir uma resposta contrária, de aumento no mRNA e na própria proteína GFAP. Surpreendentemente, este efeito da corticosterona era revertido se os astrócitos fossem co-cultivados com neurônios (MELCANGI et al., 2001), um achado que sugere uma complexa interação entre os dois tipos celulares e fornece uma explicação plausível para os resultados discrepantes in vivo e in vitro.

Ainda em astrócitos, demonstrou-se que a metilprednisolona e a DX aumentaram os níveis de cálcio citossólico, bem como de glutamina sintetase e glutamina desidrogenase, ambas importantes no metabolismo do glutamato em tais células (MELCANGI et al., 2001), assim demonstrando que a expressão de muitas outras proteínas astrocitárias, além da GFAP, pode ser modulada pela administração de corticoides. Este fato sinaliza que os corticoides podem exercer amplos efeitos morfológicos e funcionais não só em células da linhagem astrocitária, mas também, de forma indireta, sobre a atividade neuronal via modulação da ação de neurotransmissores, como o glutamato, o qual é normalmente captado e removido do microambiente neuronal pela ação astrocitária (SOFRONIEW \& VINTERS, 2010).

O’CALLAGHAN et al. (1991) observaram que a administração de corticosterona por cinco dias a quatro meses reduziu em 20 a $40 \%$ a expressão de GFAP no hipocampo, mesencéfalo e córtex cerebral de ratos. A adrenalectomia, por sua vez, resultou num aumento da expressão dessa proteína a partir do 12 o dia pós-cirurgia e persistindo por até quatro meses, elevação esta revertida pela subsequente administração de corticosterona nos ratos previamente adrenalectomizados.

Segundo ALONSO (2000), os glicocorticoides foram capazes de inibir a proliferação de células progenitoras de oligodendrócitos (células $\mathrm{NG}^{+}$) em várias regiões da substância branca e cinzenta do SNC de ratos adultos. Uma vez que a proliferação de tais células desempenha um papel fundamental no processo de remielinização, esses resultados levantam a possibilidade de efeitos deletérios no reparo do tecido nervoso a partir de tratamentos terapêuticos de traumas do SNC baseados na administração de glicocorticoides. Atraso na

Ciência Rural, v.43, n.3, mar, 2013. 
remielinização oligodendroglial após injeção de droga gliotóxica foi igualmente observado no tronco encefálico de ratos tratados com DX (BONDAN et al., 2004). Ao mesmo tempo, a regulação negativa de GFAP exercida pelos esteroides adrenais sugere que os aumentos de GFAP encontrados na cicatriz glial após injúria podem ser atenuados pela administração de glicocorticoides. Entretanto, O’CALLAGHAN et al. (1991) encontraram que a administração crônica de corticosterona em ratos não foi capaz de reverter ou diminuir os grandes aumentos de expressão de GFAP causados por dano encefálico induzido por trauma ou intoxicação. Dessa forma, os autores sugerem que glicocorticoides e injúria parecem regular a expressão de GFAP por mecanismos distintos.

A maior expressão de GFAP na medula espinhal em relação à ponte, independentemente do uso de DX ou não, reflete as notáveis diferenças de densidade astrocitária encontradas em distintas áreas do SNC (EMSLEY \& MACKLIS, 2006).

Uma vez que ainda permanece indefinido o exato papel do aumento da expressão astrocitária de GFAP após agressão nervosa e discute-se se a própria formação da cicatriz glial no SNC representaria uma influência benéfica ou deletéria no reparo tecidual (SOFRONIEW \& VINTERS, 2010), a redução do conteúdo de GFAP demonstrada neste estudo pelo uso da DX em cães não permite generalizar e inferir, de forma precisa, as reais implicações do uso de corticoides na prática clínica no âmbito da recuperação morfológica e funcional do SNC após situações de agressão. Apesar das complexas e não inteiramente elucidadas interações celulares envolvidas na manutenção da homeostasia no microambiente neural, o que se pode constatar neste estudo é que o emprego de DX em cães esteve ligado a uma redução da expressão de GFAP, o principal marcador da população astrocitária no SNC, à semelhança do já constatado em alguns estudos in vitro, bem como realizados experimentalmente em roedores.

\section{COMITÊ DE ÉTICA E BIOSSEGURANÇA}

Protocolo número 23/2011

\section{REFERÊNCIAS}

ALONSO, G. Prolonged corticosterone treatment of adult rats inhibits the proliferation of oligodendrocyte progenitors present throughout white and gray matter regions of the brain. Glia, v.31, p.219-231, 2000.

BONDAN et al. Ultrastructural study of the remyelinating process following local ethidium bromide injection in the brainstem of dexamethasone-immunosuppressed rats. Arquivos de NeuroPsiquiatria, v.62, p.131-138, 2004. Disponível em: <http://dx.doi. org/10.1590/S0004-282X2004000100023>. Acesso em: 12 nov. 2011. doi: 10.1590/S0004-282X2004000100023.

CHENG, J.D.; de VELLIS, J. Oligodendrocytes as glucocorticoids target cells: functional analysis of the glicerol phosphate dehydrogenase gene. Journal of Neuroscience Research, v.59, p.436-445, 2000.

EMSLEY, J.G.; MACKLIS, J.D. Astroglial heterogeneity closely reflects the neuronal-defined anatomy of the adult murine CNS. Neuron Glia Biology, v.2, p.175-186, 2006. Disponível em: <http://www.ncbi.nlm.nih.gov/pmc/articles/PMC1820889>. Acesso em: 11 nov. 2011. doi: 10.1017/S1740925X06000202.

GUILPAIN, P.; LE JEUNNE, C. Anti-inflammatory and immunosuppressive properties of corticosteroids. Presse Médicale, v.41, p.378-383, 2012. Disponível em: <http://www. em-consulte.com/article/703896/alertePM>. Acesso em: $9 \mathrm{dez}$. 2011. doi: 10.1016/j.lpm.2012.01.010.

JUNG-TESTAS, I. et al. Actions of steroid hormones and growth factors on glial cells of the CNS and PNS. Journal of Steroid Biochemistry and Molecular Biology, v.48, p.145-154, 1994.

MELCANGI, R.C. et al. Glial cells: a target for steroid hormones. In: CASTELLANO-LÓPEZ, B.; NIETRO-SAMPEDRO, M. Glial cell function. Amsterdam: Elsevier, 2001. p.31-40.

MONTGOMERY, D.L. Astrocytes: form, functions, and roles in disease. Veterinary Pathology, v.31, p.145-167, 1994.

O'CALLAGHAN, J.P. et al. Glucocorticoids regulate the synthesis of glial fibrillary acidic protein in intact and adrenalectomized rats but do not affect its expression following brain injury. Journal of Neurochemistry, v.57, p.860-869, 1991

ORSINI, H. et al. Marcação imunoistoquímica da expressão astrocitária de proteína glial fibrilar ácida e de vimentina no sistema nervoso central de cães com cinomose. Arquivos de Neuro-Psiquiatria, v.65, p.1070-1077, 2007. Disponível em: <http://dx.doi.org/10.1590/S0004-282X2007000600032>. Acesso em: 26 out. 2011. doi: 10.1590/S0004-282X2007000600032.

SOFRONIEW, M.V.; VINTERS, H.V. Astrocytes: biology and pathology. Acta Neuropathologica, v.119, p.7-35, 2010. Disponível em: <http://www.springerlink.com/content/ yt3g342215343602/>. Acesso em: 25 out. 2011. doi: 10.1007/ s00401-009-0619-8. 